\title{
PENGARUH MODEL PEMBELAJARAN INQUIRY TRAINING BERBANTUAN MULTIMEDIA TERHADAP PENGUASAAN KONSEP FISIKA PESERTA DIDIK
}

\author{
Wildan Hidayat*, Muhammad Taufik, Gunawan \\ Program Studi Pendidikan Fisika, Universitas Mataram \\ *Email: wildan.physic11@ gmail.com \\ DOI: http://dx.doi.org/10.29303/jpft.v5i1.948
}

\begin{abstract}
This research aim to examine the effect of multimedia assisted inquiry training learning model for students physic concept mastery. This type of research is quasi experiment with non-equivalent control group design. The research population was all students of XI MIA MAN 2 Mataram with a purposive sampling technique. The XI MIA 4 class was chosen as the experimental class and the XI MIA 3 class as the control class. Hypothesis testing using independent t-test with 5\% of significance level. Hypothesis testing yielded the concept mastery t count is 3.20 higher than the t table which has a value of 1.99. Based on the provisions, Ho is rejected and it is concluded that there are differences in mastery of physics concepts due to the practice of multimedia assisted inquiry training learning model. It means that there is a better increase of concepts mastery in the experimental class than the control class. This result can be proved by the $N$-gain test, where there is an increase of 53.92\% in the medium category for concept mastery in the experimental class greater than the control class with an increase of $41.92 \%$ in the medium category.
\end{abstract}

Keywords: Inquiry Training, Interactive Multimedia, Concept Mastery

\section{PENDAHULUAN}

Pendidikan adalah salah satu bentuk perwujudan kebudayaan manusia yang dinamis dan sarat perkembangan (Trianto, 2014). Pendidikan dilaksanakan dengan tujuan mempersiapkan peserta didik agar mampu bersaing dalam kehidupan bermasyarakat (Tuqalby et al, 2017). Sekolah sebagai lembaga formal dalam melaksanakan pendidikan harus mampu memfasilitasi peserta didik untuk mengembangkan potensi yang ada di dalam dirinya sehingga dapat bersaing di era global seperti saat ini.

Ilmu Pengetahuan Alam (IPA) atau Sains merupakan pengetahuan yang diperoleh melalui pembelajaran, penguasaan, pengetahuan, proses penemuan, konsepkonsep, dan fakta-fakta yang melingkupi kebenaran dari hukum-hukum alam yang terjadi dan dapat dibuktikan melalui metode ilmiah (Ibrahim et al, 2017). Konsep-konsep sains khususnya fisika memiliki peranan penting dalam perkembangan teknologi di era global. Teknologi yang dikembangkan dapat memberikan manfaat yang besar bagi kehidupan manusia. Hal itu tidak akan terjadi tanpa memahami ilmu sains melalui proses pembelajaran.

Fisika merupakan bagian dari sains yang memfokuskan kajiannya pada materi, energi, dan hubungan antara keduanya (Gunawan et al, 2015). Fisika dalam kajiannya memiliki konsep-konsep yang bersifat nyata dan juga bersifat abstrak. Konsep fisika yang bersifat abstrak seringkali menyebabkan kesulitan bagi guru dan peserta didik dalam menjelaskan serta memahami konsep tersebut.

Studi pendahuluan yang dilakukan melalui observasi proses pembelajaran fisika kelas XI MAN 2 Mataram, menunjukkan bahwa proses pembelajaran fisika di kelas masih berpusat pada guru. Hal ini menyebabkan beberapa peserta didik selama proses pembelajaran terlihat kurang faham dengan apa yang disampaikan oleh guru. Media pembelajaran yang ada juga kurang dimanfaatkan. Keadaan tersebut berpengaruh terhadap penguasaan konsep fisika peserta didik. Oleh karena itu pembelajaran fisika harusnya disajikan 
dengan model pembelajaran yang lebih bervariasi serta memanfaatkan media yang ada.

Model pembelajaran yang dapat digunakan sebagai solusi atas permasalahan tersebut adalah model pembelajaran inquiry training berbantuan multimedia. Model pembelajaran inquiry training merupakan model pembelajaran yang dikembangkan oleh Richard Suchman (1981) untuk mengajarkan kepada para peserta didik sebuah proses untuk meneliti dan menerangkan fenomena yang tidak biasa (Joyce et al, 2015). Menurut Siapaga (2015) Model pembelajaran inquiry training adalah model yang melibatkan peserta didik secara aktif dalam pembelajaran dan bertujuan untuk melatih kemampuan peserta didik dalam meneliti, menjelaskan fenomena, dan memecahkan masalah ilmiah (Sipapaga, 2015). Berdasarkan beberapa pendapat di atas, peneliti menyimpulkan bahwa model pembelajaran inquiry training merupakan model pembelajaran yang menekankan bagaimana peserta didik dapat melakukan pencarian untuk memecahkan masalah yang mereka hadapi dengan rasa ingin tahu yang ada pada diri mereka sendiri. Tujuan umum latihan penelitian adalah membantu siswa mengembangkan disiplin intelektual dan keterampilan yang mampu untuk meningkatkan pertanyaan-pertanyaan dan pencarian jawaban yang terpendam dari rasa keingintahuan mereka (Gaol, 2014). Inquiry training terdiri dari lima fase yaitu berhadapan dengan masalah, verifikasi, eksperimentasi, merumuskan keterangan, dan analisis proses penelitian (Joyce, 2016)

Multimedia secara umum didefinisikan sebagai gabungan dari berbagai media teks, gambar, video, dan animasi dalam satu program berbasis komputer yang dapat memfasilitasi komunikasi interaktif (Munir, 2013). Pembelajaran fisika pada beberapa konsep yang abstrak seringkali menyebabkan guru kesulitan dalam menyampaikan materi, sehingga peserta didik kurang memahami materi yang disampaikan, maka peneliti menggunakan multimedia yang bertujuan untuk memberikan ilustrasi terhadap peristiwa fisika dalam bentuk yang lebih menarik dan mudah dipahami. Multimedia yang digunakan dalam penelitian ini berupa gabungan dari beberapa media seperti teks, gambar, dan animasi yang dikombinasikan menggunakan program Adobe Flash CS6 menjadi suatu multimedia baru yang dapat digunakan dalam pembelajaran.

Penguasaan konsep didefinisikan sebagai usaha yang harus dilakukan siswa dalam merekam dan mentransfer kembali sejumlah informasi dari suatu materi pelajaran tertentu yang dapat dipergunakan dalam memecahkan masalah, menganalisis, meginterpetasikan pada suatu kejadian tertentu (Silaban, 2014). Dahar (dalam Hermansyah et al, 2015) mendefinisikan penguasaan konsep sebagai kemampuan peserta didik dalam memahami makna secara ilmiah baik teori maupun penerapannya dalam kehidupan sehari-hari. Berdasarkan beberapa pendapat tersebut dapat disimpulkan bahwa penguasaaan konsep adalah kemampuan peserta didik untuk memahami makna yang dapat diungkapkan kembali dalam bentuk teori serta dapat diterapkan dalam suatu proses penyelesaian masalah. Penguasaan konsep peserta didik dapat digunakan dalam menjelaskan suatu fenomena yang mereka lihat pada lingkungan. Semakin tinggi penguasaan konsep yang dimiliki, maka semakin baik peserta didik dapat menjelaskan dan menyelesaikan permasalah yang dihadapi. Anderson dan Krathwohl (2015) menyempurnakan indikator penguasaan konsep pada taksonomi Bloom menjadi enam tingkatan yaitu mengingat, memahami, mengaplikasikan, menganalisis, mengevaluasi, dan mencipta. 


\section{METODE PENELITIAN}

Penelitian ini merupakan penelitian kuasi eksperimen, dengan desain penelitian, yaitu non-equivalent control group. Proses pembelajaran menggunakan model pembelajaran inquiry training berbantuan multimedia pada kelas eksperimen dan model pembelajaran konvensional pada kelas kontrol. Instrumen penguasaan konsep menggunakan tes pilihan ganda pada materi elastisitas dengan subjek penelitian adalah peserta didik kelas XI MIA di MAN 2 Mataram tahun ajaran 2018/2019. Kelas XI MIA 4 dipilih sebagai kelas eksperimen dan kelas XI MIA 3 sebagai kelas kontrol dengan teknik purposive sampling.

Data hasil penguasaan konsep diuji prasyarat, berupa uji homogenitas dan uji normalitas. Kemudian dilanjutkan dengan uji hipotesis menggunakan uji t polled varians. Data diuji dengan menggunakan uji N-gain secara lebih lanjut untuk mengetahui peningkatan penguasaan konsep per indikator dan per sub materi.

\section{HASIL DAN PEMBAHASAN}

Hasil penelitian yang telah dilakukan menggambarkan penguasaan konsep yang masih rendah baik pada kelas eksperimen maupun kelas kontrol. Hal ini terlihat dari nilai rata-rata tes awal penguasaan konsep masing-masing kelas. Nilai rata-rata yang masih rendah dikarenakan kedua kelas belum memperoleh materi elastisitas sesuai jenjangnya. Pengetahuan peserta didik hanya sebatas pada pengetahuan dasar yang mereka peroleh dari sekolah menengah pertama, referensi lain, atau pengalaman yang mereka alami di lingkungan sekitar.

$$
\text { Penelitian dimulai dengan }
$$

memberikan tes awal penguasaan konsep pada kedua kelas. Setelah memberikan tes awal, maka peneliti memberikan perlakuan yang berbeda pada kedua kelas. Untuk mengukur pengaruh perlakuan yang telah diberikan, kedua kelas diberikan tes akhir dengan materi, jumlah, dan bobot soal yang sama dengan tes awal. Berdasarkan hasil tes akhir, kelas eksperimen memperoleh nilai rata-rata yaitu 72,96 lebih tinggi dari kelas kontrol yang memporoleh nilai rata-rata yaitu 66,50. Peningkatan rata-rata penguasaan konsep fisika peserta didik pada kelas kontrol dan kelas eksperimen disajikan pada gambar 1.

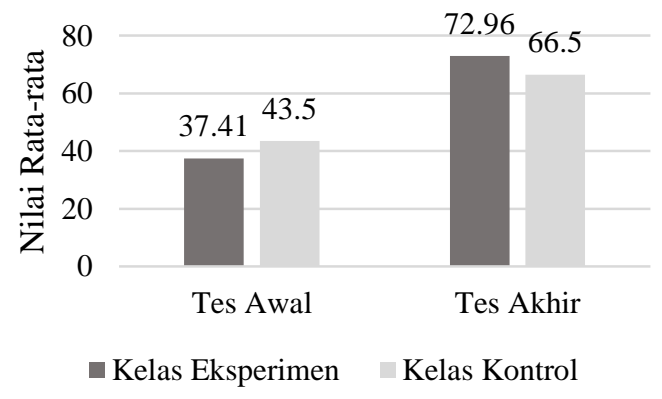

Gambar 1. Perbandingan Nilai Rata-rata Penguasaan Konsep

Berdasarkan Gambar 1 dapat dilihat bahwa terdapat perbedaan nilai antara kelas eksperimen dan kelas kontrol. Perbedaan tersebut merupakan akibat pengaruh perlakuan yang berbeda antara kedua kelas, sehingga dapat dikatakan bahwa model pembelajaran inquiry training berbantuan multimedia memberikan pengaruh terhadap penguasaan konsep fisika peserta didik.

Analisis secara statistik dilakukan untuk pembuktian lebih jauh, maka dilakukan uji normalitas dan uji homogenitas data tes awal dan tes akhir. Berdasarkan hasil tes didapatkan bahwa data terdistribusi secara normal dan homogen. Analisis selanjutnya adalah uji hipotesis menggunakan uji t independen dengan rumus polled varians dan didapatkan nilai t hitung yaitu 3,20 lebih besar dibanding $\mathrm{t}$ tabel dengan nilai 1,99. Jadi, dapat disimpulkan bahwa terdapat perbedaan penguasaan konsep yang signifikan akibat pengaruh penerapan model pembelajaran inquiry training berbantuan multimedia.

Model pembelajaran inquiry training berbantuan multimedia dapat meningkatkan penguasaan konsep fisika peserta didik 
karena peserta didiki dilatih untuk meneliti permasalahan yang diberikan, sehingga mendorong peserta didik untuk aktif dalam mencari tahu jawaban atas permasalahan tersebut. Multimedia yang digunakan dalam pembelajaran membantu dalam memvisualisasikan fenomena yang mereka hadapi selama proses pencarian jawaban. Keterlibatan aktif peserta didik dalam proses meneliti menyebabkan peserta didik dapat menguasai konsep fisika dengan baik. Hal ini diperkuat dengan penelitian sebelumnya mengenai model pembelajaran inquiry training, yaitu menurut Sani (2010) yang menyimpulkan bahwa kelas eksperimen yang diajar menggunakan model pembelajaran inquiry training mempunyai tingkat penguasaan konsep yang lebih tinggi, karena kelas ekperimen mampu menjawab dengan lebih banyak tes hasil belajar dibandingkan dengan kelas kontrol. Selain itu Limba (dalam Rustaman, 2005) juga menunjukkan bahwa peningkatan keterampilan proses sains dan penguasaan konsep setelah peserta didik terlibat dalam pembelajaran konsep perpindahan kalor dengan menggunakan model latihan inkuiri (inquiry training) lebih baik secara signifikan daripada peserta didik yang mengalami pembelajaran biasa.

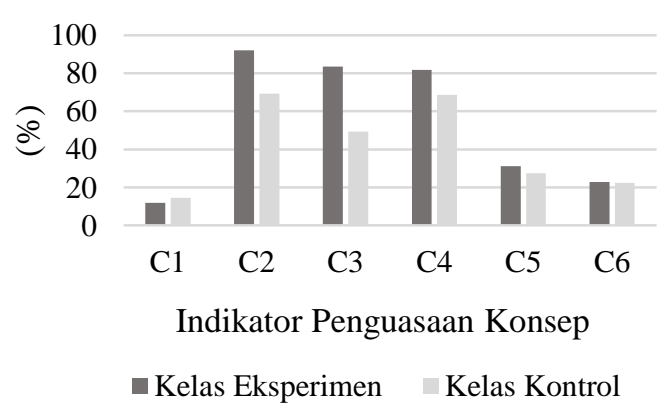

Gambar 2. Perbandingan nilai N-gain Penguasaan Konsep per Indikator

Peningkatan penguasaan konsep fisika peserta didik dapat dilihat dari hasil uji $\mathrm{N}$-gain per indikator dan per submateri. Hasil uji N-gain pada kelas eksperimen secara keseluruhan menunjukkan peningkatan yang lebih tinggi dibandingkan kelas eksperimen. Hasil uji N-gain per indikator dan per submateri disajikan pada Gambar 2 dan Gambar 3.

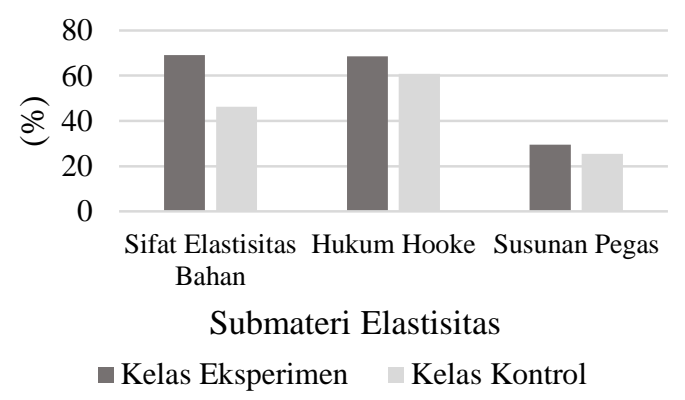

Gambar 3. Perbandingan nilai N-gain Penguasaan Konsep per Submateri

Berdasarkan Gambar 2 dan Gambar 3 terlihat bahwa secara keseluruhan penguasaan konsep peserta didik pada kelas eksperimen mengalami peningkatan yang lebih tinggi dibandingkan kelas kontrol baik per indikator penguasaan konsep maupun per submateri elastisitas. Peningkatan tersebut dikarenakan pada kelas eksperimen peserta didik membangun sendiri pengetahuannya melalului kegiatan latihan penelitian untuk menyelesaikan permasalahan yang diberikan oleh guru sehingga memiliki penguasaan konsep yang lebih baik dibandingkan kelas kontrol. Penggunaan multimedia dalam pembelajaran juga semakin memperkuat gambaran peserta didik tentang fenomena yang diteliti. Akan tertapi, dari Gambar 3 terlihat bahwa pada submateri susunan pegas tampak bahwa peningkatan yang terjadi masih rendah, hal ini terjadi karena submateri tersebut termasuk dalam soal dengan tingkatan penguasaan konsep yang tinggi yaitu C5 dan C6, dimana pada Gambar 2 tampak bahwa peningkatan pada kedua indikator tersebut juga rendah

\section{PENUTUP}

Beerdasarkan hasil penelitian, analisis data, dan pembahasan, maka dapat diambil kesimpulan bahwa model pembelajaran inquiry training berbantuan 
multimedia berpengaruh terhadap penguasaan konsep fisika peserta didik. Pengaruh tersebut dilihat dari peningkatan nilai rata-rata penguasaan konsep. Kedua kelas sama-sama mengalami peningkatan nilai rata-rata penguasaan konsep, namun berdasarkan uji N-gain dapat dikatakan kelas ekserimen mengalami peningkatan yang lebih baik dibandingkan kelas kontrol.

Model pembelajaran inquiry training dapat dijadikan alternatif pada pembelajaran fisika oleh guru. Model pembelajaran ini akan lebih baik lagi jika diterapkan dengan bantuan multimedia. Namun, dalam penerapannya diperlukan perencanaan dan persiapan yang matang agar pembelajaran dapat berjalan sesuai tujuan yang hendak dicapai. Waktu yang digunakan selama pelaksanaan pembelajaran harus digunakan secara efisien. Pembagian kelompok saat menerapkan model ini sebaiknya menggunakan kelompok dengan anggota yang tidak terlalu besar. Sebaiknya guru dapat membangkitkan keinginan peserta didik untuk bertanya megenai fakta atau masalah yang disajikan. Untuk penelitian selanjutnya mengenai model pembelajaran inquiry training dapat dilakukan pada materi yang berbeda dengan subjek penelitian yang lebih luas.

\section{REFERENSI}

Anderson, L.W \& Krathwohl, D.R. 2015. Kerangka Landasan untuk Pembelajaran, Pengajaran, dan Asesmen: Revisi Taksonomi Pendidikan Bloom. Yogyakarta: Pustaka Pelajar.

Gaol, D. K. L., \& Sirait, M. 2014. Pengaruh Model Pembelajaran Inquiry Training Menggunakan Media Powerpoint terhadap Hasil Belajar Siswa. Jurnal Inpafi 2(2), 30-39

Gunawan, G., Harjono, A., \& Sutrio, S. 2015. Multimedia Interaktif dalam Pembelajaran Konsep Listrik Bagi
Calon Guru. Jurnal Pendidikan Fisika dan Teknologi 1(1), 9-14.

Hermansyah, H., Gunawan, G., \& Herayanti, L. 2015. Pengaruh Penggunaan Laboratorium Virtual terhadap Penguasaan Konsep dan Kemampuan Berpikir Kreatif Siswa pada Materi Getaran dan Gelombang. Jurnal Pendidikan Fisika dan Teknologi 1(2), 97-102.

Ibrahim, I., Kosim, K., \& Gunawan, G. 2017 Pengaruh Model Pembelajaran Conceptual Understanding Procedures (CUPs) Berbantuan LKPD terhadap Kemampuan Pemecahan Masalah Fisika. Jurnal Pendidikan Fisika dan Teknologi 3(1), 14-23.

Joyce, B., Weil, M., \& Calhoun, E. 2015. Model-model Pengajaran Edisi ke-9. Yogyakarta: Pustaka Belajar.

Munir. 2015. Multimedia: Konsep dan Aplikasi dalam Pendidikan. Bandung: Alfabeta.

Rustaman, Y.N. 2005. Perkembangan Penelitian Pembelajaran Berbasis Inkuiri Dalam Pendidikan Sains. Makalah dipresentasikan dalam Seminar Nasional II Himpunan Ikatan Sarjana dan Pemerhati Pendidikan IPA Indonesia, FPMIPA Universitas Pendidikan Indonesia, Bandung, 22-23 Juli 2005.

Sani, A.R, \& Syihab, T.A.Z.M. 2010. Pengaruh Model Pembelajaran Inquiry Training (Latihan Inkuiri) terhadap Penguasaan Konsep Fisika Siswa Kelas X SMA Negeri 1 Tanjung Beringin. Jurnal Penelitian Inovasi Pembelajaran Fisika 2(2), 16-22.

Silaban, B. 2014. Hubungan Antara Penguasaan Konsep Fisika dan Kreativitas dengan Kemampuan Memecahkan Masalah pada Materi Pokok Listrik Statis. Jurnal Penelitian Bidang Pendidikan 20(1), 65-75. 
Sipapaga, S.D, dan Wahyuni, I. 2015. Pengaruh Model Pembelajaran Inquiry Training Terhadap Hasil Belajar Siswa pada Materi Pokok Listrik Dinamis. Jurnal Inpafi 3(4), 20-26.

Trianto, 2014. Mendesain Model Pembelajaran Inovatif, Progresif, dan Kontekstual. Jakarta: Prenadamedia Group.

Tuqalby, R., Sutrio, S., dan Gunawan, G. 2017. Pengaruh Strategi Konflik Kognitif terhadap Penguasaan Konsep pada Materi Fluida Siswa SMAN 3 Mataram tahun ajaran 2016/2017. Jurnal Pendidikan Fisika dan Teknologi 3(1), 8-13. 